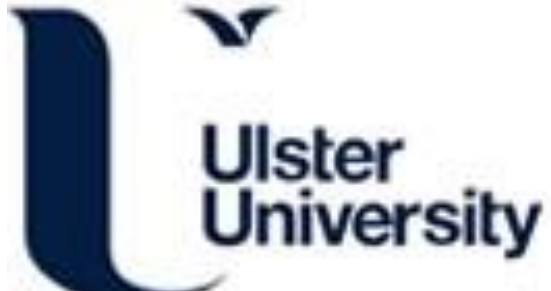

\section{Quantifying health literacy and eHealth literacy using existing instruments and browser-based software for tracking online health information seeking behavior}

Quinn, S., Bond, R., \& Nugent, C. D. (2017). Quantifying health literacy and eHealth literacy using existing instruments and browser-based software for tracking online health information seeking behavior. Computers in Human Behavior, 69(11), 256-267. https://doi.org/10.1016/j.chb.2016.12.032

Link to publication record in Ulster University Research Portal

Published in:

Computers in Human Behavior

Publication Status:

Published (in print/issue): 01/04/2017

DOI:

10.1016/j.chb.2016.12.032

Document Version

Author Accepted version

\section{General rights}

Copyright for the publications made accessible via Ulster University's Research Portal is retained by the author(s) and / or other copyright owners and it is a condition of accessing these publications that users recognise and abide by the legal requirements associated with these rights.

\section{Take down policy}

The Research Portal is Ulster University's institutional repository that provides access to Ulster's research outputs. Every effort has been made to ensure that content in the Research Portal does not infringe any person's rights, or applicable UK laws. If you discover content in the Research Portal that you believe breaches copyright or violates any law, please contact pure-support@ulster.ac.uk. 


\title{
Quantifying Health Literacy and eHealth Literacy Using Existing Instruments And Browser- based Software for Tracking Online Health Information Seeking Behavior
}

\begin{abstract}
Citizens are increasingly using Internet-based resources to obtain and understand health information at the point of need. The ability to locate, evaluate and use online health information may be influenced by an individual's level of health literacy and eHealth literacy. Those with advanced eHealth literacy skills may utilise more efficient online search strategies and identify higher quality health information resources. This paper describes a study which investigated the associations between health literacy, eHealth literacy and actual online health information seeking behavior. Accurately quantifying online health information seeking behavior can be difficult, which is why we integrated software into the web browser to objectively monitor online interactions, search queries and Uniform Resource Locators. We recruited 54 participants to search for information related to common health topics. We received 307 answers, of which $75.2 \%$ were correct. However, despite having adequate health and eHealth literacies, participants relied on search engine results as a guide to locating information resources. Furthermore $96.3 \%$ of participants utilised unaccredited health information to answer some questions. The findings suggest that eHealth literate individuals may not always utilise effective online searching strategies. Pearson's product-moment correlation indicated that the relationship between the health and eHealth literacy scores was not statistically significant.
\end{abstract}

Keywords: Health literacy, eHealth literacy, Online health information seeking behavior

\section{Introduction}

Health information seekers are increasingly using online health information to answer health related questions. The Pew Research Center's Internet and American Life Project indicates that health information seeking was the third most popular online activity measured (Fox, 2011) and that $72 \%$ of Internet users have used the world wide web to search for health information (Fox \& Duggan, 2013). The Internet provides a convenient, cost effective and private means of gaining access to health knowledge, and the motivations for seeking information are diverse. Health information seekers have used the Internet as a diagnostic tool, sought information about specific treatments and looked for others with a similar health concern (Fox \& Duggan, 2013). Individuals seek health information for a number of reasons, including (1) reassurance, (2) to reduce uncertainty, or (3) to help reconcile themselves with a new health situation (Caiata-Zufferey, Abraham, Sommerhalder, \& Schulz, 2010; Powell, Inglis, Ronnie, \& Large, 2011; Strekalova, 2016). However, doubts have been raised about the quality, accuracy, reliability and veracity of various online health information resources (Zhang, Sun, \& Xie, 2015). Moreover, there are concerns that not all health information seekers will have sufficient skills to appraise the quality of online health information (Chen \& Lee, 2014). Health Literacy is an individual's competence to obtain, understand and apply health information (Sørensen et al., 2012). The capabilities 
associated with health literacy include reading and writing skills, listening and speaking skills, numeracy skills, and cultural and conceptual knowledge (Sørensen et al., 2012). Additional capabilities include advanced cognitive skills that, along with social skills, can enable an individual to critically analyse information (Nutbeam, 2000). Inadequate health literacy has been linked to negative health practices including a lack of use of disease prevention services, poorer health and increased hospitalisations (Jacobs, Lou, Ownby, \& Caballero, 2016; World Health Organization, 2013). In the sphere of online health information seeking, low health literacy has been associated with a limited ability to evaluate online health information (Diviani, van den Putte, Giani, \& van Weert, 2015). Online information seeking presents additional complexities for the information seeker as electronic searching technologies are introduced. Norman and Skinner (2006a) introduced the concept of eHealth Literacy, which is defined as the ability to seek, locate and evaluate electronically sourced health information and apply this to a health problem. Being eHealth literate is associated with advanced skills for online health information searching. Whilst much research has focused on the relationship between eHealth literacy and online health information seeking, fewer studies have investigated both health literacy and eHealth literacy as determinants. This paper describes a study in which we explored the associations between health literacy and eHealth literacy, and an individual's skills to find and apply online health information to a popular health topic. We have chosen to investigate health information seeking from this dual perspective as online information gathering requires multiple interrelated skills. The online health information seeker requires competencies to effectively utilise searching applications and filter search results. Moreover literacy, numeracy, decision making and reasoning skills may be needed to critically evaluate the information found. These skills can be effectively measured with health literacy and eHealth literacy instruments, enabling further analysis. The remainder of the paper is as follows. Section 2 discusses related work in the field of uncertainty management, health literacy and eHealth literacy. Section 3 describes the methodology for the study and section 4 provides the results. Section 5 discusses the results, and section 6 describes the conclusions drawn from the research.

\section{Related Work}

\subsection{Online health information seeking and uncertainty management}

Health information seeking is often initiated in response to a health problem or health related anxiety (Lagoe, \& Atkin, 2015; Powell et al., 2011; Stone, Scott, Martin, \& Brashers, 2013). An information need can arise when a patient's level of knowledge is incongruent with that necessary to fulfil their health need. Uncertainty is a prevalent characteristic of health experiences such as illness (Brashers, Neidig, Haas, Dobbs, Cardillo, \& Russell, 2000; Han, Klein, \& Arora, 2011), and can occur "when details of situations are ambiguous, complex, unpredictable, or probabilistic" (Brashers, 2001). For patients and caregivers medical sources of uncertainty and insecurity can include the diagnosis, 
treatment or trajectory of a health condition, or aspects of medical decision making (Martin, Stone, Scott, \& Brashers, 2010; Oprescu, Campo, Lowe, Andsager, \& Morcuende, 2013; Stone, \& Jones, 2009; Vevea, \& Miller, 2010). Moreover, insufficient information, or the provision of information that is inaccurate, inconsistent, ambiguous or excessive can also contribute to uncertainty and confusion (Brashers, 2001; Caiata-Zufferey et al., 2010; DeLorme, \& Huh, 2009; Han et al., 2011; Martin et al., 2010; Stone, \& Jones, 2009). One strategy by which individuals may attempt to manage their uncertainty is by actively seeking information (DeLorme, \& Huh, 2009; Lagoe, \& Atkin, 2015; Stone et al., 2013; Stone, \& Jones, 2009; Thompson, Bevan, \& Sparks, 2012). Health information seeking is often differentiated from passive acquisition of health knowledge and has been described as undertaking purposeful activities to obtain health information, often to fulfil specific goals (Lambert, \& Loiselle, 2007; Niederdeppe, Hornik, Kelly, Frosch, Romantan, Stevens, Barg, Weiner, Schwartz, 2007). Online health resources have been used as a means to cope with or reduce health-related uncertainty (CaiataZufferey et al., 2010; DeLorme, \& Huh, 2009; Donovan-Kicken, \& Bute, 2008; Stone et al., 2013; Oprescu et al., 2013), and Uncertainty Management Theory (UMT) (Brashers et al., 2000), a prominent communication uncertainty framework, has been applied to appraise the associations between online health information seeking and uncertainty management (Oprescu et al., 2013; Rains, 2014; Rains, \& Tukachinsky, 2015a; Rains, \& Tukachinsky, 2015b). A central tenet of UMT proposes that uncertainty is not necessarily a negative or positive experience, but that an individual will appraise the meaning of uncertainty, and the resulting emotional response will determine whether the uncertainty is evaluated as negative, positive or neutral. The uncertainty evaluation will influence an individual's behaviors in managing their uncertainty. For example, individuals for whom uncertainty is an undesirable or negative state may seek health information to augment their knowledge and thereby lessen their state of uncertainty (Stone et al., 2013; Thompson et al., 2012). In contrast, others who perceive their uncertainty as rendering hope or optimism may strive to maintain or increase the state of uncertainty by gathering discordant information or by intentionally avoiding information that could potentially cause distress or discomfort (Barbour, Rintamaki, Ramsey, \& Brashers, 2012; Stone et al., 2013). It has been suggested that social support with gathering, examining and evaluating information, for example by friends or family members, can assist with uncertainty management (Brashers, Neidig, \& Goldsmith, 2004). Web based resources such as online communities may provide a platform for interpersonal communications which can be utilised to cope with health-related uncertainty. UMT was utilised to analyse the behaviors exhibited by the members of an online health support community for the parents and caregivers of children with clubfoot (Oprescu et al., 2013). Analysis of the information exchanges revealed that the behaviors of both information seekers and information providers were focused on uncertainty management; whilst caregivers sought to acquire information that would help them to cope with the uncertainties associated with their children's illness, those that provided advice also aimed to identify and provide knowledge that would assist information seekers with managing their uncertainties. 
Online searching tools can facilitate access to a diversity of health information resources that address both prominent and less known health issues. Rains (2014) suggested that online health information seeking behaviors such as query construction and information source selection enabled the information seeker to influence and manage information acquisition processes. Moreover, the range of information resources available provided information seekers with opportunities to identity information specific to their health needs which could subsequently be used to manage their uncertainties. A UMT based analysis of information seeking found that individuals who utilised Web based sources of health information were more successful in achieving a desired level of uncertainty when compared to individuals whom did not seek health information (Rains, 2014). Researchers have also examined the associations between the particular categories of medical content available online and uncertainty management. An investigation of online searches for skin cancer information discovered that scrutinising web page content related to the detection, prevention and treatment of skin cancer was not predictive of reaching a desirable level of uncertainty (Rains, \& Tukachinsky, 2015b). However, reading information that focused on skin cancer susceptibility and severity was associated with successful uncertainty management. UMT has also been utilised to evaluate how the searching behaviors and information-processing activities of online information seekers may affect uncertainty management. Rains and Tukachinsky (2015b) found that participants who spent longer reading health web pages, and thus were highly invested in systematic processing of the health information, achieved greater levels of uncertainty discrepancy reduction. An appraisal of online searching behaviors discovered that participants who exhibited higher levels of positivity in uncertainty appraisals exhibited a more focused approach to online health information searches, visiting fewer web pages and having longer visit durations than those with more negative appraisals (Rains, \& Tukachinsky, 2015a). The investigators proposed that those with a more optimistic perception of uncertainty may be driven to select and scrutinise information sources that confirm their current knowledge, and thereby can assist with maintaining their uncertainty levels.

Health consumers are often faced with challenging and uncertain health situations and may employ various strategies to reduce or maintain ambiguity about a health-related condition. The reviewed literature suggests that the Internet may provide an effective and valuable health information channel for health consumers that wish to utilise information strategies in order to manage health-related uncertainty.

\subsection{Health Literacy and eHealth Literacy}

The increasing utilisation of eHealth applications provide an opportunity for widespread dissemination of reliable and timely health information to health consumers. Moreover, in many cases eHealth communications can facilitate the tailoring of health messages and information to the particular needs 
and behaviors of health consumers (Kreps \& Neuhauser, 2010). However, there are various impediments to the adoption of eHealth technologies. Ehealth tools are required to be accessible, easy to use and engaging for the audience (Kreps \& Neuhauser, 2010). Moreover, the competencies of the intended audience are also of significance; if consumers do not have the necessary skills to utilise eHealth tools then as a result their effectiveness will be limited (Norman \& Skinner, 2006a). The competencies to effectively engage with eHealth are reflected in Norman and Skinner's model of eHealth literacy (2006a). The model comprises six core literacies that are subdivided into two main categories, (1) analytic and (2) context-specific. Analytic skills include the traditional skills of reading, writing and numeracy, and information literacy, an individual's ability to comprehend how information is organised. Also included in this category is media literacy, an ability to understand the composition, context and influences of media based information. Context-specific skills include health literacy and computer literacy, the ability to use computers and adapt to new software and technologies. The final literacy in this category is scientific literacy, which refers to an understanding of the scientific methodologies involved in knowledge discovery. The literacies combine to support the consumer's interaction with eHealth. However, eHealth literacy is context dependent and may be influenced by the motivation for seeking information, and the health status, presenting health issues and educational background of an individual.

Much research has identified an association between eHealth literacy and an individual's motivation to engage with online health information seeking. Those with high levels of eHealth literacy have been identified as more frequent health information seekers (Britt \& Hatten, 2013; Neter \& Brainin, 2012), and more likely to scrutinise the accuracy of information and the reliability of an information source when compared with a lower eHealth literacy group (Neter \& Brainin, 2012). Lower levels of educational attainment are often associated with reduced levels of health literacy, eHealth literacy and ineffective online searching strategies. One group of individuals that can have increased motivation to seek health information are parents that have health concerns for their children. Studies that involved the parents of children with life-threatening illnesses (Knapp et al., 2011a) and special health care needs (Knapp, Madden, Wang, Sloyer, \& Shenkman, 2011b) both revealed an association between not having a high school diploma and reduced eHealth literacy. Moreover some of the parents expressed difficulties distinguishing between high and low quality information sources and sometimes lacked the confidence to act on health information (Knapp, Madden, Wang, Sloyer, \& Shenkman, 2011b). A mixed-methods study of health literacy and the evaluation of online health information also found a correlation between lower educational achievements and limited health literacy (Diviani, van den Putte, Meppelink, \& van Weert, 2016). The study found that although adults with low health literacy were aware that the quality of online health information was variable, they were less aware of established criteria by which to assess the quality of information and were more likely to use non-established criteria. However it has also been suggested that difficulties with locating and assessing health information are not limited to those 
with lower levels of education. A survey of undergraduate nurses found that although the respondents were confident in their ability to use the Internet to gather health information, a high proportion of the students were less assured in their ability to discriminate between high and low quality health resources (Park \& Lee, 2015). A study of female college students attending a health professional degree program found variation in the students' perceived searching abilities (Stellefson, Hanik, Chaney, \& Tennant, 2012). Whilst some students reported using multiple health resources, others reported that they relied solely on a search engine to locate health information resources. Moreover some of the students reported limitations in search query formulation. An investigation into online health information seeking amongst college students found that $89 \%$ of the surveyed students were not always successful in obtaining the required health information when they searched online (Escoffery et al., 2005).

Another factor that is frequently associated with decreased levels of eHealth literacy is increased age. A study which concentrated on adults with chronic health conditions found that older adults and those with lower levels of eHealth literacy were prone to navigational needs, experiencing difficulties in finding online health information, and being less assured in their searching abilities (Lee, Hoti, Hughes, \& Emmerton, 2015). An investigation of Internet skills also found that older adults sometimes experienced problems when completing tasks that called upon operational and formal Internet skills (van Deursen \& van Dijk, 2009). This included difficulties identifying and using the browser address bar, and understanding orientation within a website. A survey that addressed the health information seeking behaviors of baby boomers and older adults found that an increase in age did correspond with a decrease in eHEALS scores (Tennant et al., 2015). However, in contrast with other research studies, the authors found that the respondents were largely positive regarding their ability to find and use Internet based health resources, although there was less confidence in their ability to differentiate between high and low quality resources.

The research studies described used a range of survey instruments, interviews and Internet based performance tests to investigate the determinants and outcomes of health literacy and eHealth literacy. In common with these studies, we have used validated instruments to measure health and eHealth literacies, in addition to Internet based search tasks to scrutinise actual health information seeking behavior (HISB). However, the main novelty in our research approach is that we endeavour to use tracking software and an algorithm to monitor, parse and analyse the user's online interactions, search strategies and the types of information resources utilised, and attempt to determine associations between these and both health literacy and eHealth literacy. Moreover, we also gather the participants' perceived difficulty in locating health information for each question and investigate whether there are any relationships between perceived difficulty and eHealth literacy. 


\section{Methods}

During the study each participant attended an online health information seeking experiment. The study had been approved by a University of Ulster Research Ethics Filter Committee, and informed consent was obtained from each participant before the experiment began. Fig. 1 indicates the protocol followed during an experiment. In the first stage the participant used a browser to search for information to answer six health questions. Following this they completed a health literacy instrument, the Newest Vital Sign (Weiss et al., 2005), and an eHealth literacy instrument, the eHealth Literacy Scale (Norman $\&$ Skinner, 2006b). In the final stage they added demographic information including age, gender and highest qualification.

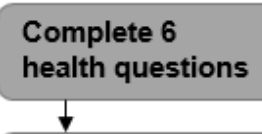

3.

eHealth Literacy

Scale (eHEALS)

4.

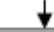

Complete demographic information

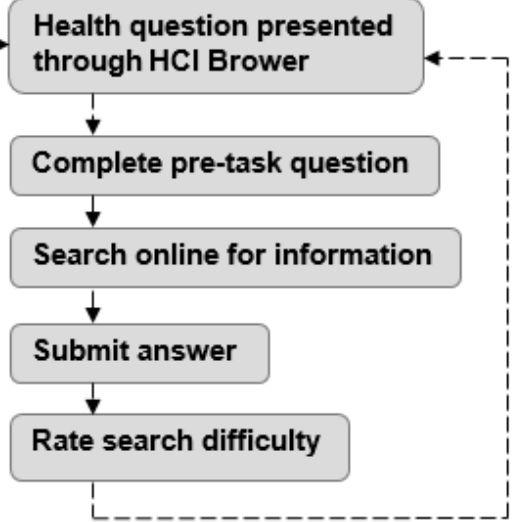

Fig. 1. Protocol for online health information seeking experiment.

\subsection{Participants}

A total of 54 subjects participated in the study, of whom $61.1 \%$ were male $(n=33)$ and $38.9 \%$ female $(\mathrm{n}=21)$. The age range of the group was 18 to 59 , with a mean age of 26.76 years $(\mathrm{SD}=9.64)$. The group included undergraduate and postgraduate university students and university staff, the majority of whom $(62.9 \%, \mathrm{n}=34)$ had achieved an undergraduate or postgraduate degree, and the remaining participants $(35.2 \%, \mathrm{n}=19)$ had a Regulated Qualifications Framework qualification at level 3 or level 4 (Crown copyright, 2016). One participant did not enter any educational information. The background disciplines of the participants included Computer Science $(70.3 \%, \mathrm{n}=38)$, Arts $(9.3 \%, \mathrm{n}=5)$, Life and Health Sciences $(7.4 \%, n=4)$, Business $(3.7 \%, n=2)$, and Social Science $(1.9 \%, n=1)$. Four participants $(7.4 \%)$ did not list a discipline.

\subsection{Health Literacy}

The Newest Vital Sign (NVS) (Weiss et al., 2005) was used to measure a participant's level of health literacy. This is a health literacy screening instrument which provides a nutritional label, accompanied by six questions that measure literacy and numeracy skills. For this study we used the NVS-UK 
(Rowlands et al., 2013), a validated version of the NVS in which the measurement scales and terminology used are consistent with UK nutrition labels. Each question is scored as correct or incorrect, resulting in a final sum score out of six. The final score is used to classify a participant's health literacy skills; a score of four or above indicates adequate health literacy skills, a score of two or three indicates intermediate health literacy skills whilst a score of one or zero indicates low health literacy skills.

\subsection{Ehealth Literacy}

The eHealth Literacy Scale (eHEALS) (Norman \& Skinner, 2006b) was used to quantify eHealth literacy. This instrument contains eight items through which a subject self-rates their ability to obtain, appraise and use electronic health information. The items are scored on a five-point Likert scale of one to five (ranging from strongly disagree to strongly agree) with a final sum score within the range of eight to 40. A higher end score indicates a higher level of eHealth literacy. Two supplementary items are also provided and can be used to evaluate a subject's general interest in using health resources on the Internet. These items were also completed by each participant.

\subsection{Health Questions}

During an online health information seeking experiment each participant was presented with six health questions and could search online for information to answer the questions. Before beginning a search the participant was asked to indicate whether they could answer the question without searching online, and could submit an answer directly if they wished. The health questions, which are listed in Table 1, focused on strategic areas such as diabetes, obesity, influenza, nutrition and analgesic medication. Each submitted answer was scored as correct or incorrect, with a final sum score out of six. The health questions were presented using the HCI Browser (Capra, 2010), which is a Mozilla Firefox extension that presented each question in turn and enabled the participant to implement their own search strategy, for example by using a search engine or entering a Uniform Resource Locator (URL) directly into the address bar. The HCI Browser also provided an interface through which an answer could be submitted, and collected timestamped browser log event data including the pages loaded, links clicked and the opening and closing of tabs. Fig. 2 presents a screen capture of the HCI Browser and an example log event data file. 
Table 1. Health questions presented to a participant during an online health information seeking experiment.

\begin{tabular}{|c|c|c|}
\hline & Health Question & Context \\
\hline 1 & $\begin{array}{l}\text { You have a headache and buy a packet of Co- } \\
\text { Codamol tablets from the chemist. Which are } \\
\text { the two largest ingredients in Co-Codamol } \\
\text { tablets? }\end{array}$ & $\begin{array}{l}\text { Co-Codamol is one of the most frequently } \\
\text { prescribed analgesic medications by General } \\
\text { Practitioners in Northern Ireland (Business } \\
\text { Services Organisation, n.d.). }\end{array}$ \\
\hline 2 & $\begin{array}{l}\text { Body mass index (BMI) is a measurement that } \\
\text { indicates whether your weight is appropriate } \\
\text { for your height. During a visit to your } \\
\text { physician your BMI is determined to be } 27 \text {. } \\
\text { What category does your BMI fall into? }\end{array}$ & $\begin{array}{l}\text { The prevalence of obesity in the UK is } 29.8 \% \\
\text { (World Health Organization, 2016a). The BMI } \\
\text { index is commonly used to classify obesity and } \\
\text { overweight in adults (World Health } \\
\text { Organization, 2016b). }\end{array}$ \\
\hline 3 & $\begin{array}{l}\text { Diabetic Retinopathy is an eye complication } \\
\text { associated with Diabetes. Can you name } 3 \\
\text { common symptoms of this condition? }\end{array}$ & $\begin{array}{l}\text { The prevalence of diabetes in the UK is } 7.7 \% \\
\text { (World Health Organization, 2016a). Diabetic } \\
\text { retinopathy is the most common cause of } \\
\text { blindness among people of working age in the } \\
\text { UK (Diabetes UK, 2016). }\end{array}$ \\
\hline 4 & $\begin{array}{l}\text { The } 5 \text { A DAY message in the UK encourages } \\
\text { people to eat five portions of fruit and } \\
\text { vegetable every day. If you were to eat } 5 \\
\text { portions of vegetables, of the recommended } \\
\text { weight, in one day, how many grammes of } \\
\text { vegetables would you eat in total? }\end{array}$ & $\begin{array}{l}\text { It is a UK government recommendation that } \\
\text { adults eat five portions of fruit and vegetables } \\
\text { each day (Public Health England, 2016). }\end{array}$ \\
\hline 5 & $\begin{array}{l}\text { One widely publicised UK health message is } \\
\text { that in most cases antibiotics should not be } \\
\text { used to treat a common cold. Why is this } \\
\text { advice given? }\end{array}$ & $\begin{array}{l}\text { It is a widely promoted health message in the } \\
\text { UK that antibiotics should not be used to treat } \\
\text { a common cold (Department of Health, 2016). }\end{array}$ \\
\hline 6 & $\begin{array}{l}\text { Hypoglycemia (low blood glucose levels) is a } \\
\text { complication of Diabetes. The unit of } \\
\text { measurement for blood glucose level is } \\
\text { Millimoles per litre (mmol/l). In terms of this } \\
\text { measurement how is Hypoglycemia defined in } \\
\text { the UK? }\end{array}$ & $\begin{array}{l}\text { Self-monitoring for symptoms of } \\
\text { Hypoglycemia is a recommended treatment for } \\
\text { diabetes (World Health Organization, 2016c). }\end{array}$ \\
\hline
\end{tabular}


(a)

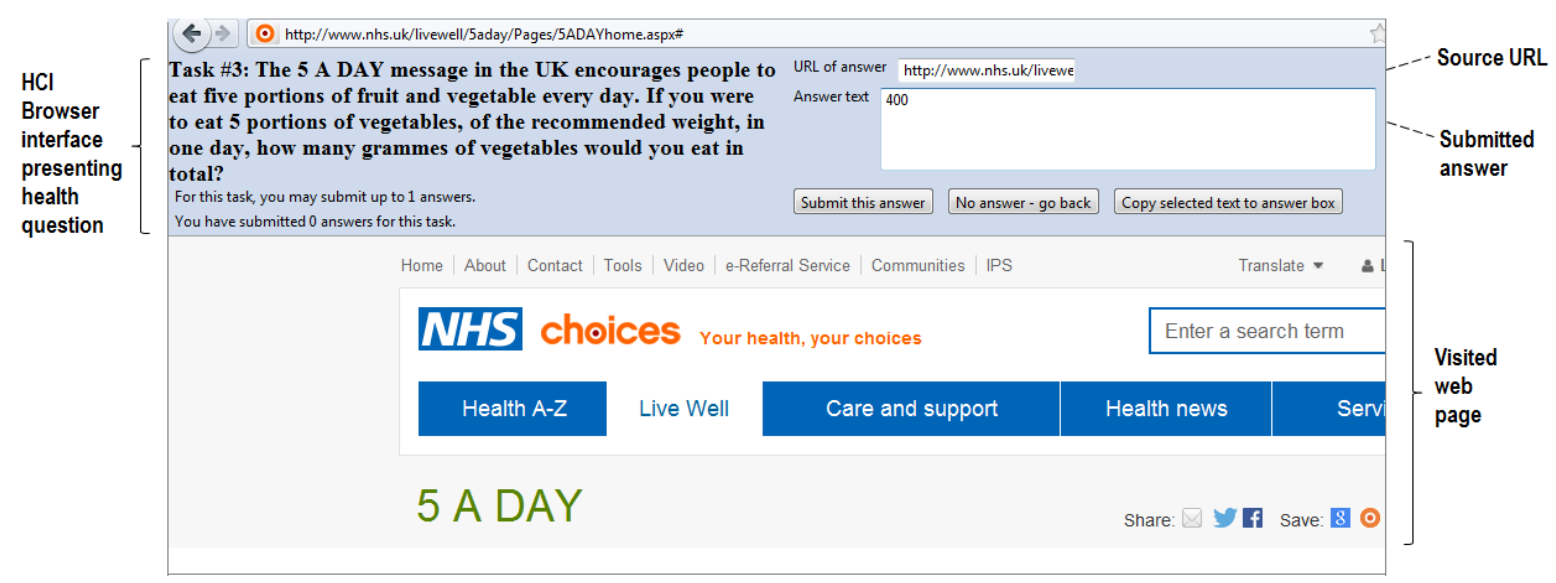

(b)

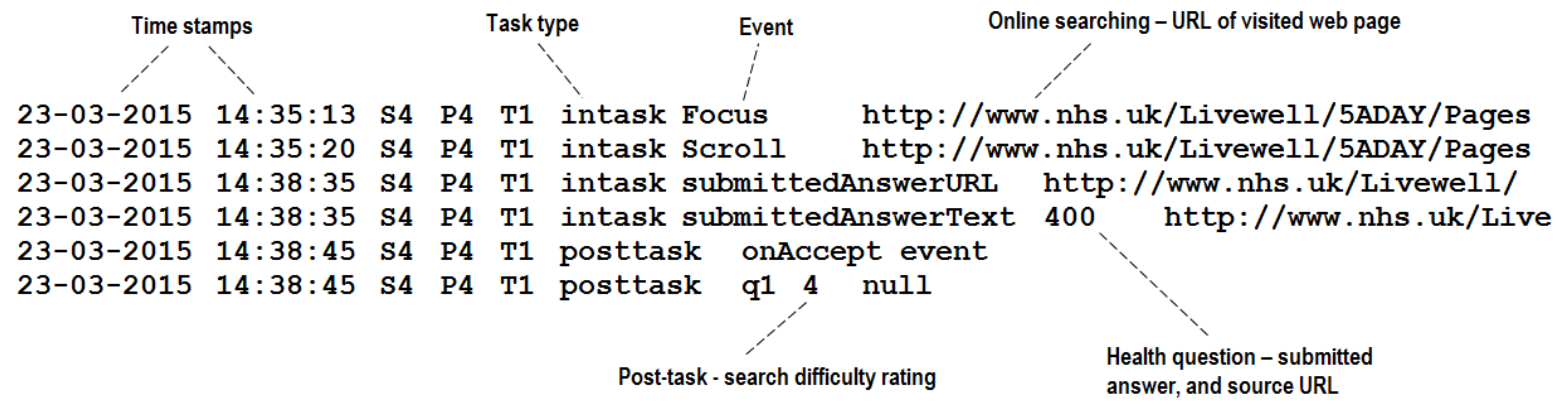

Fig. 2. HCI Browser components (a) screen capture of HCI Browser interface for submitting a health question answer and, (b) log file containing records for web page visit, health question answer and post-task question choice.

A screen capture was also recorded as the participant worked through the six health questions. On completing a question the participant could rate, on a scale of one to five (very easy to very difficult), how difficult it had been to locate the information necessary to answer the question.

In this study, a new Java based parsing program was also implemented to process the HCI Browser log files, and output these as a spreadsheet which could be utilised for further statistical analysis. The output included the search queries entered, the web pages visited and the duration of each visit. This HCI Parser has been made freely available online (Quinn, 2016) since it fully complements the HCI Browser plugin and can be used by non-technical researchers to undertake similar studies. An excerpt of the HCI Parser algorithm developed in this study has been described in Fig. 3. 
Input: A log file record which is of type string

webPageObj $\longleftarrow$ null

recordArr $[\longleftarrow$ tokenise log file record using tab as delimiter

dateStr $\longleftarrow$ recordArr $[n]$

tokenise dateStr $\longrightarrow$ day, month, year, then convert to int values

timeStr $\longleftarrow$ recordArr $[n]$

tokenise timeStr $\longrightarrow$ second, minute, hour, then convert to int values

webPageObj.timestamp $\longleftarrow$ use int values to construct Java Calendar

object

URLStr $\longleftarrow$ recordArr $[n]$

if $U R L$ is valid then

webPageObj.URL $\longleftarrow$ URLStr

if URL has query strings then

webPageObj.queryStr $\longleftarrow$ extract query strings from

webPageObj.URL

if URL has valid domain then

webPageObj.domain $\longleftarrow$ extract domain from webPageObj.URL

webPagesArr $[n] \longleftarrow$ webPageObj

webPagesArr $[n-1]$.duration $\longleftarrow$ webPagesArr $[n]$.timestamp -

webPagesArr $[n-1]$.timestamp

Fig. 3. Pseudo-code that describes the processing of a log file record for a visit to a web page. A record is tokenized, and tokens are stored in an array. Timestamp entries are converted to integer values and used to construct a Calendar object. The timestamp, web page URL, query strings and domain are stored in a web page object. The timestamp is used to calculate the visit duration of the previously visited web page.

\subsection{Statistical Analysis}

Bivariate analysis of the data was conducted using SPSS version 22. Descriptive statistics were used to calculate the mean and standard deviation of the NVS, eHEALS and health question scores, and Pearson's product-moment correlation was used to evaluate the correlations between these scores. Multiple regression analysis was also used to determine whether demographic variables were significant predictors of NVS and eHEALS scores. Chi-square analysis was also used to investigate the associations between various characteristics of HISB.

\section{Results}

\subsection{Health literacy, eHealth literacy and health questions}

The NVS scores indicated that $77.8 \%(n=42)$ of the participants had adequate health literacy skills, $14.8 \%(n=8)$ had intermediate health literacy skills whilst $7.4 \%(n=4)$ had low health literacy skills. The mean NVS score was 4.61 (SD 1.69) out of six. Analysis of the internal consistency of eHEALS 
found high reliability, $\alpha=.84$. The eHEALS scores ranged from 17 to 40 , with a mean score of 29.74 (SD 5.52). The correlation between the NVS and eHEALS scores was not statistically significant $\left(\mathrm{r}_{(52)}\right.$ $=.190, \mathrm{p}=.169)$. The results from the eHEALS supplementary items suggested that the majority of participants had a positive perception of Internet based health resources; $74.1 \%,(n=40)$ indicated that the Internet was useful in helping them make decisions about health, and $87.0 \%(n=47)$ indicated that it was important to them to be able to access health resources on the Internet. Moreover many of the participants appeared confident in their ability to use the Internet as a source of health information; $85.2 \%(n=46)$ agreed that they knew how to use the Internet to answer health questions, and $66.7 \%(n$ $=36$ ) agreed that they had the skills required to evaluate health resources found on the Internet.

A number of studies have identified age and educational attainment as determinants of an individual's level of health literacy and eHealth literacy, therefore we developed two regression models in order to investigate whether these characteristics had any predictive ability on the health literacy and eHealth literacy scores of the study population. Table 2 shows the results of multivariate regression conducted using NVS scores as the dependent variable, and qualification level and age as explanatory independent variables. The regression model represented a statistically significant proportion of the variance $\left(\mathrm{R}^{2}=\right.$ $.250, \mathrm{~F}=8.509, \mathrm{p}=.001$ ), however only qualification level was a significant predictor of NVS score. Multivariate regression analysis was also carried out for the eHEALS scores however the variance explained by the model was not statistically significant $\left(\mathrm{R}^{2}=.096, \mathrm{~F}=2.715, \mathrm{p}=.076\right)$.

Table 2. Results of multiple regression for NVS scores.

\begin{tabular}{lllll}
\hline & B & SE B & $\boldsymbol{\beta}$ & p \\
\hline Constant & 2.377 & .692 & & \\
Qualification Level & .438 & .116 & .508 & .000 \\
Age & -.003 & .024 & -.019 & .886 \\
\hline $\mathrm{R}^{2}=.250$ & & & &
\end{tabular}

All participants were able to answer at least one of the health questions correctly. The majority of subjects $(81.5 \%, n=44)$ answered four or more of the health questions correctly, $13 \%(n=7)$ gained a full score of six and $3.7 \%(n=2)$ answered only one question correctly. The mean score was 4.28 (SD $=1.24)$. Pearson's product-moment correlation was used to evaluate whether any associations existed between the question score achieved and a participant's level of health literacy, eHealth literacy or highest qualification. Health question scores had a statistically significant weak positive correlation with NVS score $\left(\mathrm{r}_{(52)}=.39, \mathrm{p}<.01\right)$ and qualification level $\left(\mathrm{r}_{(52)}=.38, \mathrm{p}<.01\right)$. However, there was no 
significant correlation between question score and the eHEALS score. These correlations have also been presented in the form of scatter plots in Fig. 4.

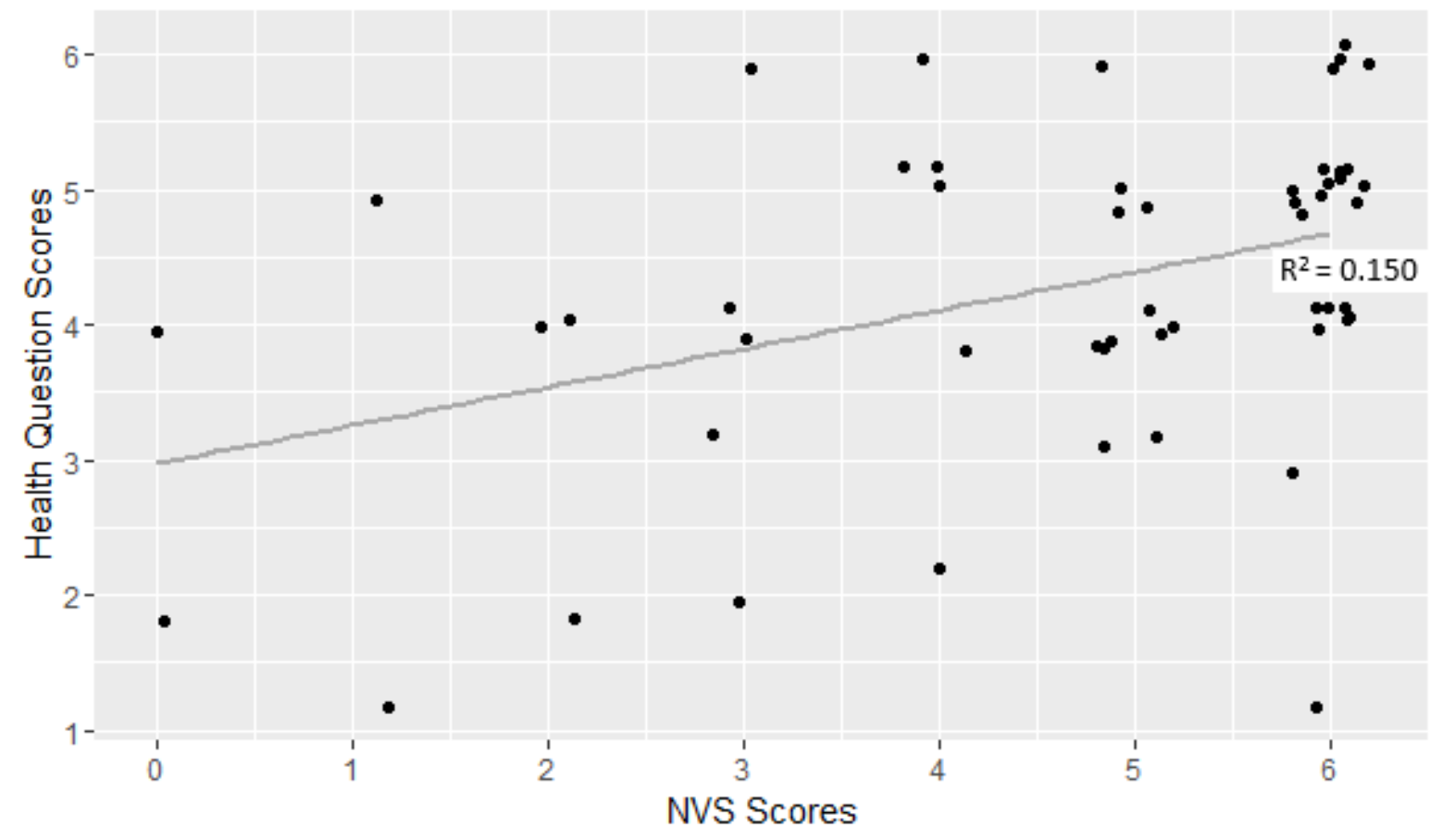

(a)

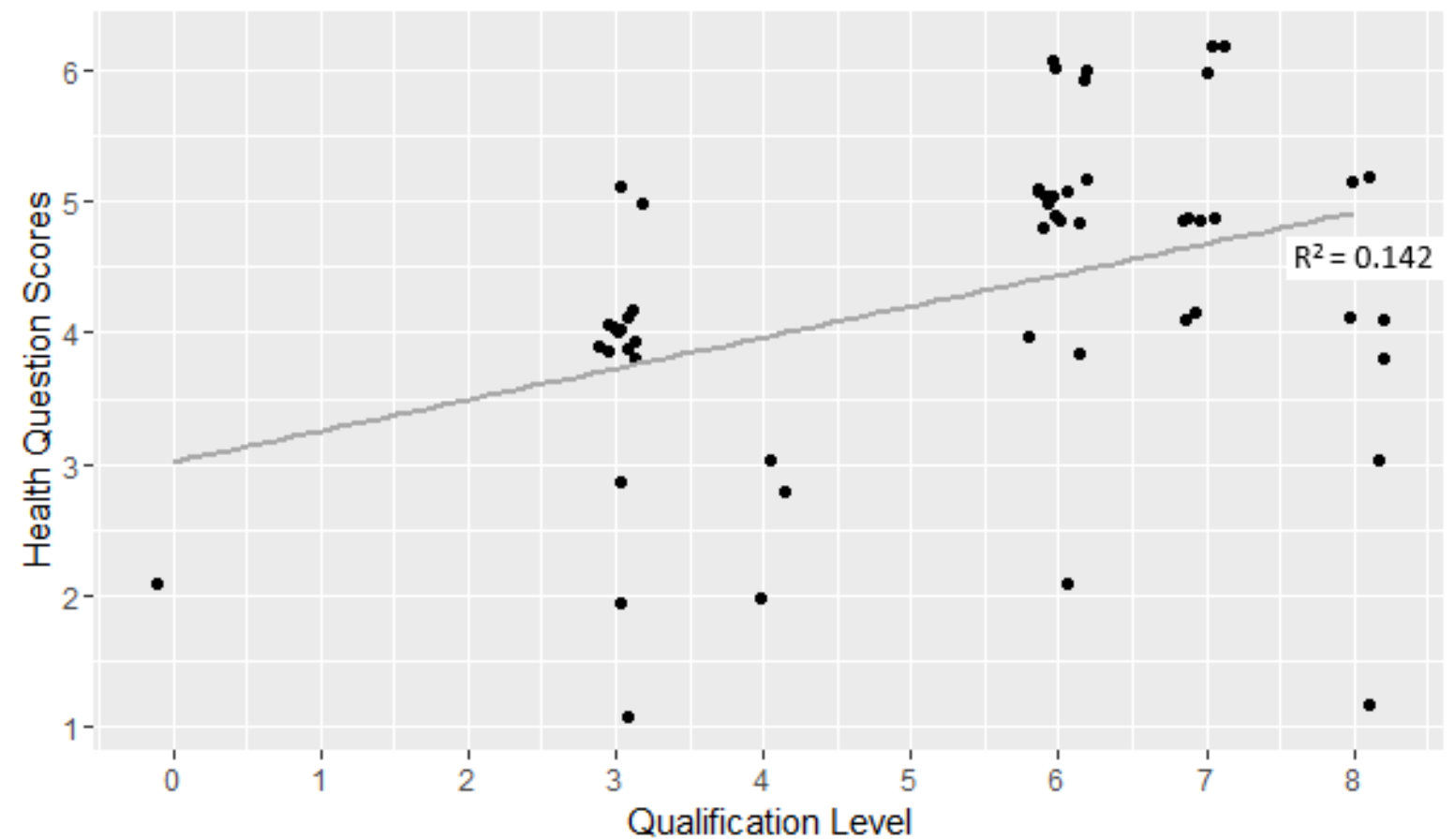

(b) 


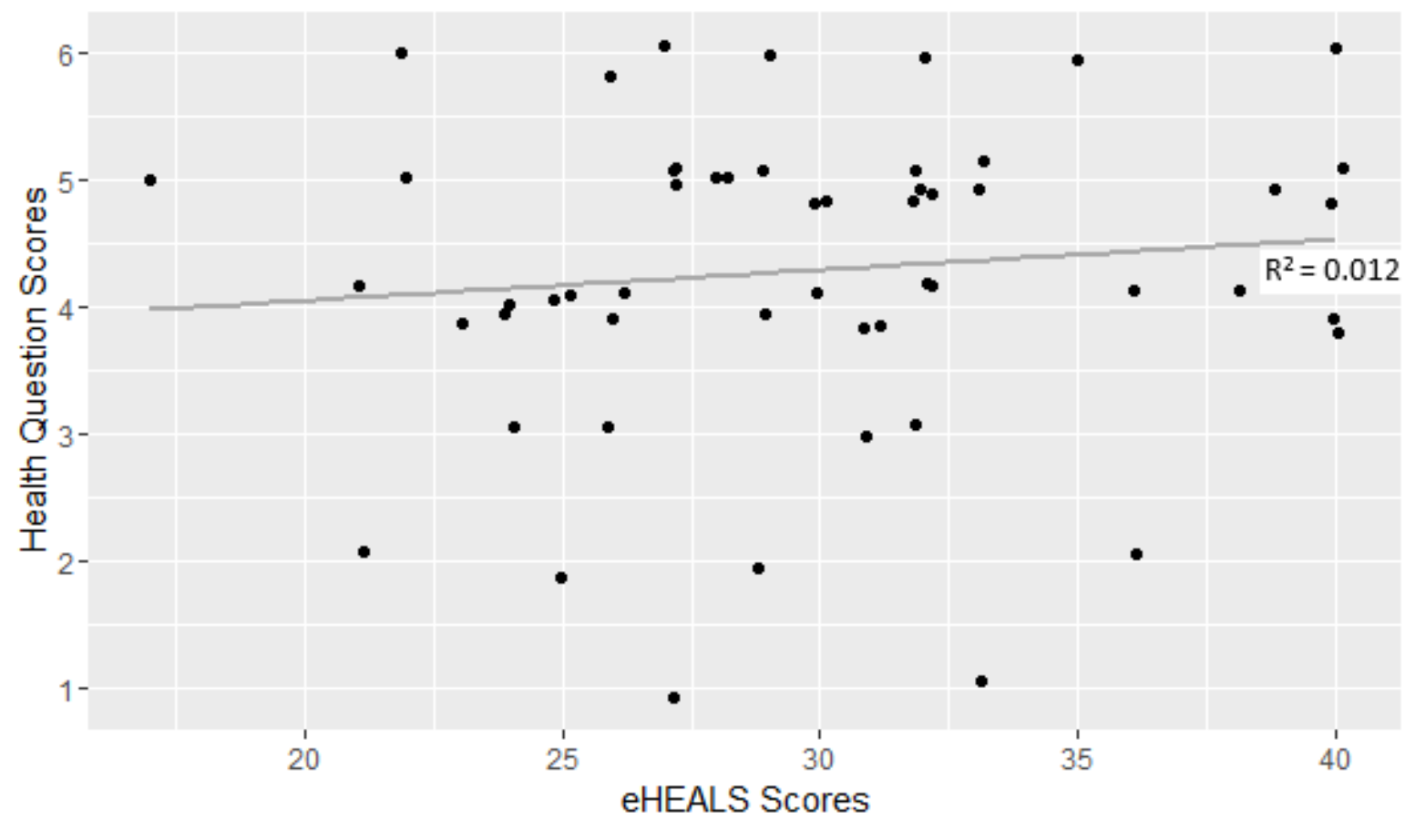

(c)

Fig. 4. Scatterplots with linear regression line illustrating correlations between (a) question score and NVS score, (b) question score and qualification level, and (c) question score and eHEALS score.

\subsection{Health Information Seeking Behavior}

Fig. 5 indicates the total submitted and correct answers for each question, and Fig. 6 indicates the average completion times for correct and incorrect answers. Table 3 illustrates paired $t$-test analysis of the completion times for all the health questions. As can be perceived, there was variation in the completion rate and the time taken to complete each health question. There was a statistically significant weak negative correlation between completion times and question scores for questions $1\left(\mathrm{r}_{(52)}=-.450\right.$, $\mathrm{p}<.01)$ and $3\left(\mathrm{r}_{(52)}=-.371, \mathrm{p}<.01\right)$. However the correlations for questions $2,4,5$ and 6 were not statistically significant. Question 4 had the lowest completion rate $(\mathrm{n}=44)$ and the lowest proportion of correct answers $(\mathrm{n}=25)$. Moreover as indicated in Table 3 the mean completion time for question 4 was significantly longer when compared to all other questions. Question 3 had the highest rate of correct answers $(\mathrm{n}=49)$ and a chi-square test of independence indicated that, with statistical significance, the participants performed best in this question, $X^{2}(5)=39.885^{\mathrm{a}}, \mathrm{p}<.001$. 


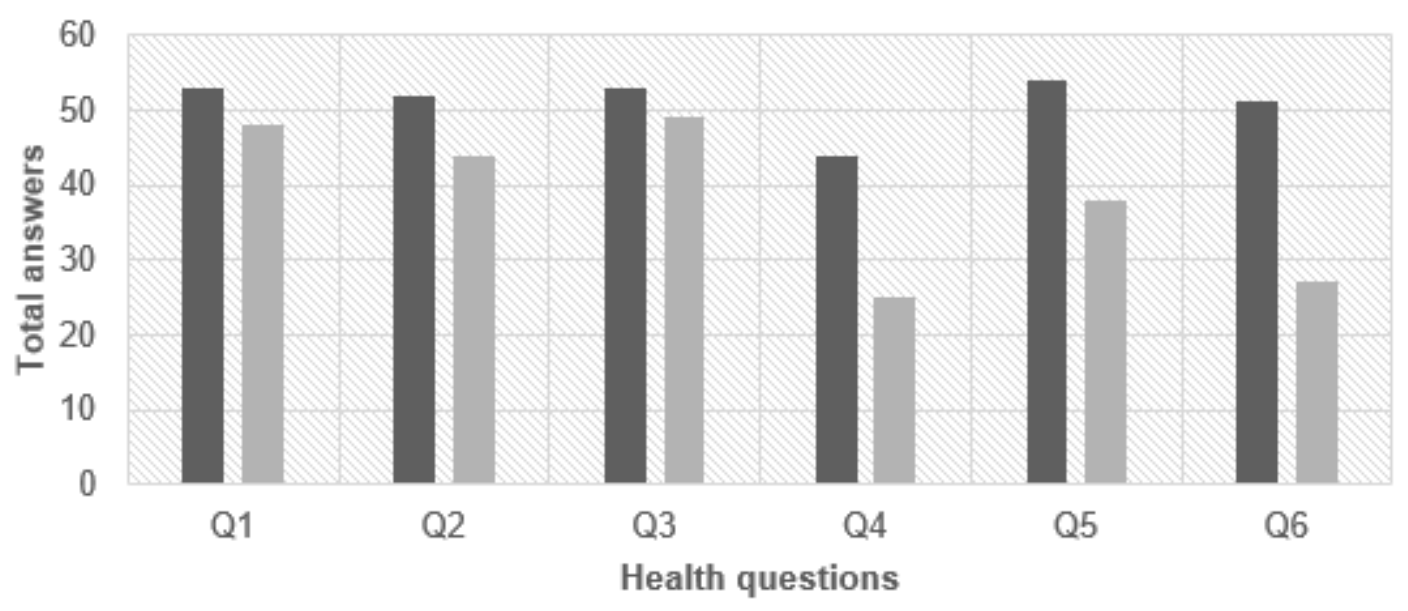

- Total answers submitted $\quad$ - Total correct answers

Fig. 5. Total submitted and correct answers for health questions.

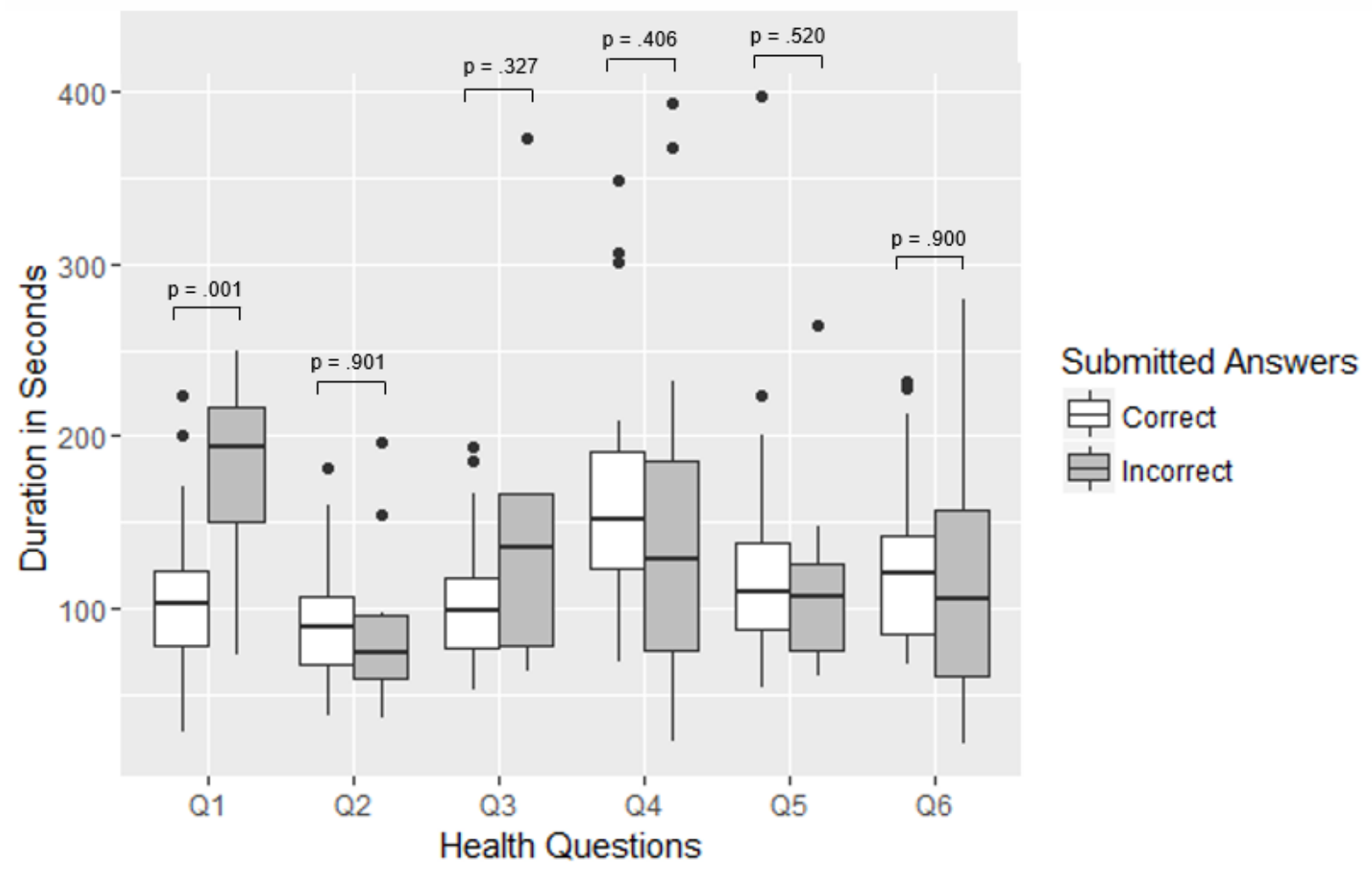

Fig. 6. Boxplots of completion times for correct and incorrect answers, including p-values from $t$ test comparison. 
Table 3. Results of $t$-test comparison of the completion times for the health questions, indicating $t$ statistic and p-value.

\begin{tabular}{lllllllll}
\hline & $\mathbf{Q 1}$ & $\mathbf{Q 2}$ & $\mathbf{Q 3}$ & $\mathbf{Q 4}$ & $\mathbf{Q 5}$ & $\mathbf{Q 6}$ & Mean & SD \\
\hline Q1 & & $\mathbf{3 . 0 8 1 * *}$ & .830 & $\mathbf{- 3 . 0 1 6 * *}$ & -.406 & -.747 & 114.43 & 50.67 \\
Q2 & $\mathbf{- 3 . 0 8 1 * *}$ & & -1.927 & $\mathbf{- 6 . 6 8 0 * * *}$ & $\mathbf{- 3 . 2 8 4 * *}$ & $\mathbf{- 3 . 1 7 1 * *}$ & 90.54 & 34.39 \\
Q3 & -.830 & 1.927 & & $\mathbf{- 4 . 1 0 0 * * * *}$ & -1.404 & -1.550 & 106.43 & 49.20 \\
Q4 & $\mathbf{3 . 0 1 6 * *}$ & $\mathbf{6 . 6 8 0 * * *}$ & $\mathbf{4 . 1 0 0 * * *}$ & & $\mathbf{2 . 9 2 9 * *}$ & $\mathbf{2 . 5 5 8 *}$ & 156.63 & 79.66 \\
Q5 & .406 & $\mathbf{3 . 2 8 4 * *}$ & 1.404 & $\mathbf{- 2 . 9 2 9 * *}$ & & -.339 & 118.61 & 57.60 \\
Q6 & .747 & $\mathbf{3 . 1 7 1} * *$ & 1.550 & $\mathbf{- 2 . 5 5 8 *}$ & .339 & & 122.06 & 61.07 \\
\hline
\end{tabular}

$* \mathrm{p}<.05, * * \mathrm{p}<.01, * * * \mathrm{p}<.001$ (two tailed).

As the health questions related to popular health topics and had been designed to be of equal difficulty it was unclear why there was such variation in the submission and accuracy rates. Therefore we aimed to explore the health information seeking behavior exhibited throughout the experiment in order to determine whether behaviors differed between questions. The most prominent method for seeking information throughout the experiment was through a search engine. As there was such a reliance on search engine result pages (SERPs) to find sources of health information we conducted $t$-test analysis to determine if there were any distinctions between the time spent on SERPs during each of the six health questions. The results of this analysis are illustrated in Table 4.

Table 4. Results of $t$-test comparison of SERPs visit duration during health questions, indicating $t$ statistic and p-value.

\begin{tabular}{lllllllll}
\hline & $\mathbf{Q 1}$ & $\mathbf{Q 2}$ & $\mathbf{Q 3}$ & $\mathbf{Q 4}$ & $\mathbf{Q 5}$ & $\mathbf{Q 6}$ & Mean & SD \\
\hline Q1 & & $\mathbf{2 . 5 8 *}$ & $\mathbf{5 . 2 3 * * *}$ & -.733 & 1.996 & .55 & 21.46 & 19.93 \\
Q2 & $\mathbf{- 2 . 5 8 *}$ & & $\mathbf{4 . 0 5 * * *}$ & $\mathbf{- 2 . 7 4 * *}$ & -.21 & -1.84 & 14.82 & 12.80 \\
Q3 & $\mathbf{- 5 . 2 3 * * *}$ & $\mathbf{- 4 . 0 5 * * *}$ & & $\mathbf{- 5 . 1 3 * * *}$ & $\mathbf{- 3 . 2 8 * *}$ & $-\mathbf{4 . 9 0 * * *}$ & 7.46 & 10.01 \\
Q4 & .733 & $\mathbf{2 . 7 4 * *}$ & $\mathbf{5 . 1 3 * * *}$ & & $\mathbf{2 . 4 4 *}$ & 1.14 & 24.37 & 24.60 \\
Q5 & -1.996 & .21 & $\mathbf{3 . 2 8 * *}$ & $\mathbf{- 2 . 4 4 *}$ & & -1.52 & 15.28 & 16.09 \\
Q6 & -.55 & 1.84 & $\mathbf{4 . 9 0 * * *}$ & -1.14 & 1.52 & & 19.80 & 18.61 \\
\hline
\end{tabular}

$* p<.05, * * p<.01, * * * p<.001$ (two tailed).

Question 4 had the largest total of time spent on visits to SERPs (mean time per subject $=24.37$ seconds, $\mathrm{SD}=24.60$ ), and the mean visit duration was significantly longer than the mean time for questions 2,3 and 5. Question 3 had the smallest total of time spent on SERPs (mean time per subject $=7.46$ seconds, 
$\mathrm{SD}=10.01$ ), and this was significantly smaller than the mean time for all other questions. However on further investigation it became apparent that the reduced time on SERPs during question 3 could be attributed to the HISB of the participants. The majority of participants $(92.6 \%, n=50)$ only visited one SERP and found a link to the source that they used to answer the question. The remaining participants $(n=4)$ only visited two SERPs before locating an answer source. In comparison the total number of SERPs visited during question 4 was much larger. Again most of the participants $(79.6 \%, n=43)$ found an answer source from the first or second SERP visited, however the remaining participants $(16.7 \%, \mathrm{n}$ =9) carried out at least three distinct searches and visited at least three distinct SERPs during their searching activities; 9.3\% $(n=5)$ visited three distinct SERPs, 5.6\% $(n=3)$ visited four distinct SERPs and one participant (1.9\%) visited five distinct SERPs. The higher rates of distinct searches during question 4 suggests that participants may have found it more challenging to find the information they sought than during question 3 . The mean SERP visit duration for question 4 was more than double the mean duration for question 3, implying that on average participants spent substantially longer reading through the search results during question 4. Again this suggests that participants may have found it more problematic to identify suitable sources of information from the search results during question 4 . The scrolling behavior exhibited during question 4 also suggests that many participants read through a larger number of the search results than they did in question 3. During question 3 the majority of participants $(75.9 \%, \mathrm{n}=41)$ chose an answer source from the first four results presented and did not scroll down the SERP to look at any further results. In total only 11 participants (20.4\%) scrolled beyond the first four SERP results. In comparison 28 participants (51.9\%) scrolled beyond the first four results on at least one of the SERPs that they visited during question 4. This would suggest that many participants found it more demanding to locate suitable information resources during question 4 and scrutinised the search results more extensively than they did in question 3.

Throughout the experiment the participants visited different sources of information including government, academic and commercial websites, accredited sources of health information and unaccredited sources of health information such as blogs. Question 4 had the largest sum total of time spent on information web page visits (mean time per subject $=67.87$ seconds, $\mathrm{SD}=66.42$ ) and question 2 had the smallest (mean time per subject $=30.72$ seconds, $\mathrm{SD}=24.46$ ). Table 5 provides the results of $t$-test comparison of the mean time spent on information pages during the experiment. Again no clear patterns are apparent. Although there is a significant time difference between question 4 and questions $1,2,5$ and 6 there is no significant difference with question 3. The mean time for question 2 is significantly smaller than the mean time for questions 3,4 and 5 , however no significant difference exists with questions 1 and 6 . An investigation of the HISB of the participants during question 2 clarified the reasons why the mean visit duration was low. In total 23 participants $(42.9 \%)$ visited only one information web page, and used this source to answer the question. In addition $18.5 \%(\mathrm{n}=10)$ used a SERP to answer the question and did not visit any information pages at all. It was surprising to note 
that question 2 had the second highest rate of visits to information pages $(n=61)$ whilst question 4 had the highest rate $(n=64)$. However the mean information page visit duration during question 2 was less than half of the mean duration for question 4. This implies that on average participants spent twice as long reading an information page during question 4 than they did in question 2, again suggesting that participants found it problematic to locate the information required for question 4 .

Table 5. Results of $t$-test comparison of information page visit duration during health questions, indicating $t$ statistic and p-value.

\begin{tabular}{lllllllll}
\hline & $\mathbf{Q 1}$ & $\mathbf{Q 2}$ & $\mathbf{Q 3}$ & $\mathbf{Q 4}$ & $\mathbf{Q 5}$ & $\mathbf{Q 6}$ & Mean & SD \\
\hline Q1 & & 1.86 & -1.24 & $\mathbf{- 2 . 4 5 *}$ & -.63 & -.02 & 41.39 & 37.02 \\
Q2 & -1.86 & & $\mathbf{- 3 . 0 2 * *}$ & $\mathbf{- 4 . 1 2 * * *}$ & $\mathbf{- 2 . 3 5 *}$ & -1.66 & 30.72 & 24.46 \\
Q3 & 1.24 & $\mathbf{3 . 0 2 * *}$ & & -1.65 & .57 & 1.25 & 51.65 & 44.81 \\
Q4 & $\mathbf{2 . 4 5 *}$ & $\mathbf{4 . 1 2 * * *}$ & 1.65 & & $\mathbf{2 . 0 3 *}$ & $\mathbf{2 . 4 9 *}$ & 67.87 & 66.42 \\
Q5 & .63 & $\mathbf{2 . 3 5 *}$ & -.57 & $\mathbf{- 2 . 0 3 *}$ & & .60 & 46.78 & 46.81 \\
Q6 & .02 & 1.66 & -1.25 & $\mathbf{- 2 . 4 9 *}$ & -.60 & & 41.56 & 43.51 \\
\hline
\end{tabular}

${ }^{*} \mathbf{p}<.05, * * \mathbf{p}<.01, * * * \mathbf{p}<.001$ (two tailed).

In total we received 307 submitted answers, of which $75.2 \%(n=231)$ were correct. Over half of the total submitted answers $(56.0 \%, \mathrm{n}=172)$ used accredited sources of information and $82.6 \%(\mathrm{n}=142)$ of these answers were correct. A much smaller proportion of the submitted answers $(21.8 \%, \mathrm{n}=67)$ used unaccredited sources and $67.2 \%(\mathrm{n}=45)$ of these answers were correct. There was a notable use of SERPs as an information source; $17.9 \%(\mathrm{n}=55)$ of the submitted answers were gathered from SERPs, and over half of these answers $(65.5 \%, \mathrm{n}=36)$ were correct. The results of a Chi-Square test of independence indicated a significant association between the information source (accredited, unaccredited or SERP) and whether the submitted answer was correct, $\mathrm{X}^{2}(2)=10.230, \mathrm{p}<.01$. Only two participants $(3.7 \%)$ used accredited sources to answer all six questions. There was no distinct pattern as to the usage of SERPs to gather information. Over half of the participants $(53.7 \%, \mathrm{n}=29)$ used information from a SERP to answer at least one question, while 3.7\% $(\mathrm{n}=2)$ used SERPs to answer five out of six health questions. However no significant correlations were found between the number of answers from SERPs and NVS scores, eHEALS scores, age or qualification level.

With regard to the overall distribution of the time online during the study, the majority of time (73\%) was spent on information pages whilst $27 \%$ of the time was spent on SERPs. The prominent method used to find information was through SERPs, however there were no statistically significant correlations between NVS and eHEALS scores and the amount of time that a participant spent on visits to SERPS 
or information pages. In total 393 search queries were entered during the experiments. There were 86 reformulations of queries and $36 \%(n=31)$ of these were spelling reformulations, all of which were auto-corrections suggested by the search engine. A notable trait amongst the study population was that, in general, the participants did not compare information between different sources. For $61.6 \%(n=189)$ of the submitted answers the participant used information from the first information page that they visited and did not visit any other information resources. Furthermore for $14.7 \%(n=45)$ of the submitted answers the participant gathered information from a SERP and did not visit any additional SERPs or any information pages at all.

\subsection{Difficulty Ratings}

At the end of each health question the participant would indicate, on a scale of one to five (very easy to very difficult), how difficult it had been to find the information necessary to answer the question. The ratings enabled us to quantify whether the participants perceived information gathering to be more or less challenging during particular questions. Fig. 7 shows the frequencies of ratings for each question. We used Spearman's correlation coefficient to investigate whether there were any associations between the ratings provided for each question and the eHEALS score. The eHEALS scores had a weak negative association with the ratings for question $1\left(\mathrm{r}_{(52)}=-.332, \mathrm{p}<.05\right)$, question $2\left(\mathrm{r}_{(52)}=-.356, \mathrm{p}<.01\right)$ and question $6\left(\mathrm{r}_{(52)}=-.424, \mathrm{p}<.01\right)$, indicating that an increase in eHEALS score correlates with a decrease in the difficulty ratings assigned. However this relationship was not true for all the health questions as the correlations for questions 3,4 and 5 were not statistically significant.

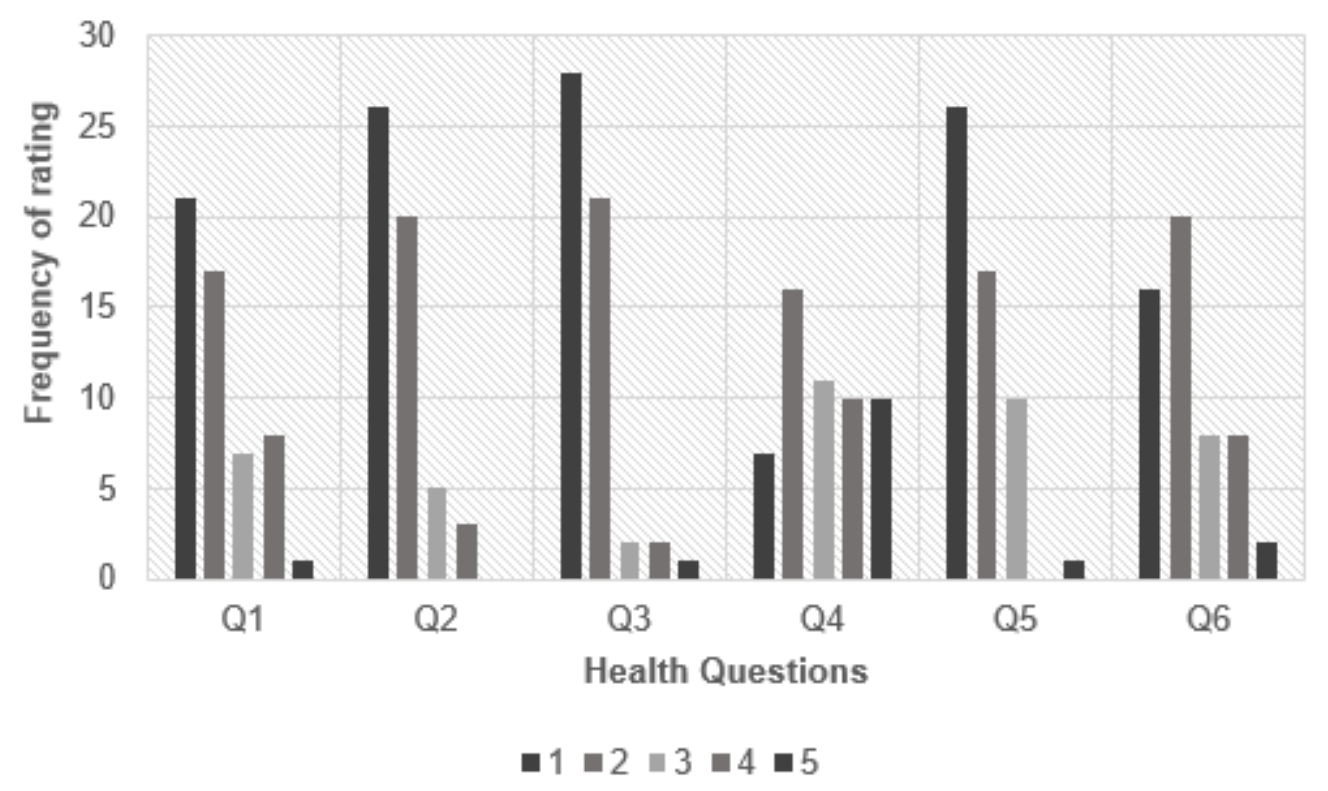

Fig. 7. Frequencies of information gathering difficulty rating for health questions. 


\section{Discussion}

The aim of this study was to discover whether there are any relationships between how an individual obtains and utilises online health information, and their level of health literacy and eHealth literacy. There was a high level of educational attainment amongst the participants and the majority of participants had adequate health literacy scores. Although there was a wider distribution in the eHealth literacy scores over half of the study population perceived their skills as being in the upper quadrant. Attitudes towards Internet based health resources were largely positive as most of the participants perceived these as useful and convenient. Participants were also confident in their ability to use the Internet to gather health information. Education was found to be a significant predictor of health literacy, and this finding concurs with the results of similar research in the domain of health literacy (Diviani, van den Putte, Meppelink, \& van Weert, 2016; Kandula et al., 2009). However surprisingly neither education nor age were significant co-variants of the eHEALS scores, and no significant relationship was identified between the NVS and eHEALS scores. As health literacy is one of the core literacies of eHealth literacy it was unexpected that no correlation was found between the two scores. Moreover whilst a weak positive correlation was found between health question scores and NVS scores, no relationship was found between the question scores and eHEALS scores. Again this was surprising as higher eHEALS scores have been associated with enhanced online searching skills, and success at finding and using health information (Neter \& Brainin, 2012). The eHEALS scores suggested that most of the participants had adequate skills to find the information necessary to answer all the health questions. However the lack of correlation with the question scores suggests that the eHEALS scores may not have accurately reflected the actual online health information seeking abilities of all the participants in our study. This finding corresponds with concerns that have been expressed regarding the validity of eHEALS as an instrument to quantify actual online health information seeking skills (Diviani, van den Putte, Meppelink, \& van Weert, 2016; van der Vaart et al., 2011). Moreover it has also been suggested that as eHEALS is a measure of self-efficacy the score may reflect an individual's overestimation of their skills rather than their actual abilities (Aponte \& Nokes, 2015; Diviani, van den Putte, Meppelink, \& van Weert, 2016; van der Vaart et al., 2011). However we could not quantify whether this was the case with our study population.

Although there was variation in the health question scores all the participants were able to use online health information to correctly answer at least one health question. The low submission rate and manner of health information seeking suggested that question 4 was the most challenging for the participants. However it was unclear why this question appeared so problematic. The majority of participants whom did not submit an answer or submitted an incorrect answer had adequate health literacy and eHealth literacy skills, thereby suggesting that they would have sufficient skills to locate and use the information required to answer this question. For a small proportion of participants it appeared that appropriate 
information was gathered but an error was introduced whilst calculating the total number of grammes. Although there was some variation in the performance of the participants for the health questions there were notable similarities in their HISB. It had been emphasised to the participants that they were free to choose their own search strategy however the most frequent online seeking method for discovering health information was through search engine results. This behavior is comparable to the searching activities of other online health information seekers (Escoffery et al., 2005; Fox \& Duggan, 2013). Throughout the experiment, participants prominently utilised SERPs to locate sources of information. Moreover search engine auto-corrections were also used to guide search query reformulation. This behavior was inconsistent with our expectations as $66.7 \%(\mathrm{n}=36)$ of participants had indicated that they knew where to find online health resources. In order to quantify the use of SERPs we measured the duration of SERP visits by a participant. However we found no significant correlation between SERPs visit duration and health literacy or eHealth literacy. Employing a search engine based searching strategy did not appear to adversely affect information gathering as the majority of participants were able to locate sources to help them answer all six questions.

Despite having adequate health literacy and eHealth literacy skills most individuals utilised both accredited and uncertified health information. This included a significant proportion of participants who utilised information from SERPs to answer the questions. The use of unaccredited health information sources and SERPs was surprising as $70.4 \%(n=38)$ of participants had agreed that they could distinguish between high and low quality online health resources. However although several participants used SERPs to answer more than one question we could not find any significant predictors for this behavior. Another notable behavior was that, in general, the participants did not appear to compare information between different sources. Almost all of the participants stopped searching at the page from which they had answered the question. For a large proportion of the questions the answer source was the first page visited, thereby these participants made no effort to compare or validate this information with any other sources.

Many of the participants were highly confident in their online searching skills, however question scores and searching behaviors did not appear to reflect the eHealth literacy competencies for a number of participants. In order to further analyse and explicate some of the inconsistencies in our findings we should also consider how contextual factors may have influenced the health information seeking behaviors of some of the participants. Online health information is often sought when health consumers perceive a risk or uncertainty regarding a personal or familial health situation (Chavarria et al., 2016; Powell et al., 2011). Health uncertainty often effects an emotional response such as anxiety or distress, and thereby the consumer may place greater value on the credibility and reliability of health information and adapt their search behaviors accordingly. Studies have suggested that when seeking information for salient health concerns online information seekers may undertake a more exploratory searching approach, performing multiple searches and examining various sources to compare and verify 
information, and placing greater significance on the reliability of the information source (Best, GilRodriguez, Manktelow, \& Taylor, 2016; Mendes, Abreu, Vilar-Correia, \& Borlido-Santos, 2016; Pang, Verspoor, Chang, \& Pearce, 2015; Powell et al., 2011; Rozmovits, \& Ziebland, 2004) However, in contrast, the study participants did not have emotive motivations for searching for health information, and this may have influenced their engagement with the search tasks. As the topics under investigation were not personally relevant, some of the participants may have been less inclined to validate the information found, verify the reliability of the information source or persist in a challenging search situation. As a result, for some participants, the searching behaviors exhibited and question score achieved may not have accurately depicted their actual skills to locate and use online health information. This may have been reflected in some of our findings including the lack of correlation between the eHEALS scores and question scores.

\section{Study Limitations}

There were a number of limitations in this study. Firstly, the participants were drawn from a convenience sample of university students and staff and thus it was likely that the level of educational attainment would be high, and consequently health literacy and eHealth literacy levels would also be high for most of the study population. However, the findings show that there was diversity in the range of scores achieved in NVS and eHEALS. Moreover, although the study population perceived themselves to be advanced users of the Internet for health information seeking purposes, the study highlighted some limitations in the effectiveness of their searching behaviors. A second limitation was that the study was performed under laboratory conditions and it is likely that the participants completed the search tasks in less time than they would take if they were actually seeking information for a genuine health concern. However, by presenting the participants with questions related to popular public health topics, we were able to comprehend a range of HISB that were typical of daily online health information seeking.

\section{Conclusion}

This study presented subjects with health questions related to popular health topics. All of the participants exhibited health literacy and eHealth literacy competencies to utilise a variety of health resources to accurately answer the health questions. The most notable behavior during the study was a reliance on search engines to guide information gathering, a common trait amongst online health information seekers (Fox \& Duggan, 2013). Other prominent characteristics of our study population included a reliance on unaccredited health information, and a reluctance to confirm the validity of health information by comparing it with other sources. Although in many cases the unaccredited information was accurate, these behavioral traits are concerning within such a highly qualified and confident group of health information seekers. Online health information is accessed by individuals of all ages and socioeconomic and educational backgrounds (Fox \& Duggan, 2013), thereby not all information seekers will have skills comparable to our participants to interpret, critique and apply the information found. One 
possible approach to alleviating the problems associated with limited health information seeking skills could be public health promotion of criteria by which to assess the validity of online health information. Providing standardised evaluation criteria could assist information seekers of all abilities to effectively identify unreliable information sources. There is also an opportunity to enhance the health literacy and eHealth literacy skills of adolescents and young adults through education in schools, colleges and universities. This also has the benefit of equipping younger generations with eHealth literacy skills that can inform their health decisions as their health needs change throughout adult life.

Some of the more unexpected results in our study related to the weak correlations between the eHEALS scores, the NVS scores and the health question scores. Although eHEALS has been repeatedly validated as a reliable measure of eHealth literacy skills it did not appear to accurately reflect the online health information seeking skills of all our participants. This suggests that there may be a need to develop a new eHealth literacy measurement instrument which relies less on the user's self-perception of their skills. One approach could be to expand the question set to more rigorously examine the user's past experiences of using a range of eHealth tools and engaging with the various skills that comprise the literacies of eHealth literacy. The results from these questions may capture a more accurate reflection of the user's actual online health information seeking skills.

\section{References}

Aponte, J., \& Nokes, K. M. (2015). Electronic health literacy of older hispanics with diabetes. Health Promotion International, doi:10.1093/heapro/dav112

Barbour, J. B., Rintamaki, L. S., Ramsey, J. A., \& Brashers, D. E. (2012). Avoiding health information. Journal of Health Communication, 17(2), 212-229.

Best, P., Gil-Rodriguez, E., Manktelow, R., \& Taylor, B. J. (2016). Seeking help from everyone and no-one: Conceptualizing the online help-seeking process among adolescent males. Qualitative Health Research, 26(8), 1067-1077. doi:10.1177/1049732316648128 [doi]

Brashers, D. E. (2001). Communication and uncertainty management. Journal of Communication, 51(3), 477-497.

Brashers, D. E., Neidig, J. L., \& Goldsmith, D. J. (2004). Social support and the management of uncertainty for people living with HIV or AIDS. Health Communication, 16(3), 305-331. 
Brashers, D. E., Neidig, J. L., Haas, S. M., Dobbs, L. K., Cardillo, L. W., \& Russell, J. A. (2000). Communication in the management of uncertainty: The case of persons living with HIV or AIDS. Communications Monographs, 67(1), 63-84.

Britt, R. K., \& Hatten, K. N. (2013). Need for cognition and electronic health literacy and subsequent information seeking behaviors among university undergraduate students. SAGE Open, 3(4), 2158244013508957.

Business Services Organisation. (n.d.). Prescribing by GP Practice. Retrieved July 27, 2016, from, http://www.hscbusiness.hscni.net/services/2471.htm

Caiata-Zufferey, M., Abraham, A., Sommerhalder, K., \& Schulz, P. J. (2010). Online health information seeking in the context of the medical consultation in Switzerland. Qualitative Health Research, 20(8), 1050-1061.

Capra, R. (2010). HCI browser: A tool for studying web search behavior. Proceedings of the American Society for Information Science and Technology, 47(1), 1-2.

Chavarria, E. A., Chaney, E. H., Stellefson, M. L., Chaney, J. D., Chavarria, N., \& Dodd, V. J. (2016). Types and factors associated with online health information seeking among college men in latino fraternities: A qualitative study. American Journal of Men's Health, doi:1557988315626510 [pii]

Chen, W., \& Lee, K. (2014). More than search? informational and participatory eHealth behaviors. Computers in Human Behavior, 30, 103-109. doi:http://dx.doi.org/10.1016/j.chb.2013.07.028

Crown copyright. (2016). Compare different qualifications. Retrieved July 27, 2016, from https://www.gov.uk/what-different-qualification-levels-mean/compare-different-qualification-levels

DeLorme, D. E., \& Huh, J. (2009). Seniors' uncertainty management of direct-to-consumer prescription drug advertising usefulness. Health Communication, 24(6), 494-503.

Department of Health. (2016). Antibiotics. Retrieved July 27, 2016, from, http://www.nhs.uk/Conditions/Antibiotics-penicillins/Pages/Introduction.aspx

Diabetes UK. (2016). EYES (RETINOPATHY). Retrieved July 27, 2016, from, https://www.diabetes.org.uk/Guide-to-diabetes/Complications/Retinopathy/ 
Diviani, N., van den Putte, B., Giani, S., \& van Weert, J. C. (2015). Low health literacy and evaluation of online health information: A systematic review of the literature. Journal of Medical Internet Research, 17(5), e112. doi:10.2196/jmir.4018 [doi]

Diviani, N., van den Putte, B., Meppelink, C. S., \& van Weert, J. C. M. (2016). Exploring the role of health literacy in the evaluation of online health information: Insights from a mixed-methods study. Patient Education and Counseling, 99(6), 1017-1025. doi:http://dx.doi.org/10.1016/j.pec.2016.01.007

Donovan-Kicken, E., \& Bute, J. J. (2008). Uncertainty of social network members in the case of communication-debilitating illness or injury. Qualitative Health Research, 18(1), 5-18. doi:10.1177/1049732307309005 [doi]

Escoffery, C., Miner, K. R., Adame, D. D., Butler, S., McCormick, L., \& Mendell, E. (2005). Internet use for health information among college students. Journal of American College Health, 53(4), 183188.

Fox, S. (2011). Health Topics. Retrieved July 27, 2016, from http://www.pewinternet.org/2011/02/01/health-topics-2/

Fox, S., \& Duggan, M. (2013). Health Online 2013. Retrieved July 27, 2016, from http://www.pewinternet.org/2013/01/15/health-online-2013/

Han, P. K., Klein, W. M., \& Arora, N. K. (2011). Varieties of uncertainty in health care: A conceptual taxonomy. Medical Decision Making, 31(6), 828-838. doi:10.1177/0272989X11393976 [doi]

Jacobs, R. J., Lou, J. Q., Ownby, R. L., \& Caballero, J. (2016). A systematic review of eHealth interventions to improve health literacy. Health Informatics Journal, 22(2), 81-98. doi:10.1177/1460458214534092 [doi]

Kandula, N. R., Nsiah-Kumi, P. A., Makoul, G., Sager, J., Zei, C. P., Glass, S., Stephens, Q., \& Baker, D. W. (2009). The relationship between health literacy and knowledge improvement after a multimedia type 2 diabetes education program. Patient Education and Counseling, 75(3), 321-327. doi:http://dx.doi.org/10.1016/j.pec.2009.04.001

Knapp, C., Madden, V., Marcu, M., Wang, H., Curtis, C., Sloyer, P., \& Shenkman, E. (2011a). Information seeking behaviors of parents whose children have life-threatening illnesses. Pediatric Blood \& Cancer, 56(5), 805-811. doi:10.1002/pbc.22674 
Knapp, C., Madden, V., Wang, H., Sloyer, P., \& Shenkman, E. (2011b). Internet use and eHealth literacy of low-income parents whose children have special health care needs. Journal of Medical Internet Research, 13(3), e75.

Kreps, G. L., \& Neuhauser, L. (2010). New directions in eHealth communication: Opportunities and challenges. Patient Education and Counseling, 78(3), 329-336.

doi:http://dx.doi.org/10.1016/j.pec.2010.01.013

Lagoe, C., \& Atkin, D. (2015). Health anxiety in the digital age: An exploration of psychological determinants of online health information seeking. Computers in Human Behavior, 52, 484-491. doi:http://dx.doi.org/10.1016/j.chb.2015.06.003

Lambert, S. D., \& Loiselle, C. G. (2007). Health information seeking behavior. Qualitative Health Research, 17(8), 1006-1019. doi:17/8/1006 [pii]

Lee, K., Hoti, K., Hughes, J. D., \& Emmerton, L. M. (2015). Consumer Use of "Dr Google": A Survey on Health Information-Seeking Behaviors and Navigational Needs. Journal of Medical Internet Research, 17(12), e288.

Martin, S. C., Stone, A. M., Scott, A. M., \& Brashers, D. E. (2010). Medical, personal, and social forms of uncertainty across the transplantation trajectory. Qualitative Health Research, 20(2), 182196. doi:10.1177/1049732309356284 [doi]

Mendes, Á., Abreu, L., Vilar-Correia, M. R., \& Borlido-Santos, J. (2016). "That should be left to doctors, That's what they are there for!"-Exploring the reflexivity and trust of young adults when seeking health information. Health Communication, , 1-6. doi: 10.1080/10410236.2016.1199081

Neter, E., \& Brainin, E. (2012). eHealth literacy: Extending the digital divide to the realm of health information. Journal of Medical Internet Research, 14(1), e19.

Niederdeppe, J., Hornik, R. C., Kelly, B. J., Frosch, D. L., Romantan, A., Stevens, R. S., Barg, F.K., Weiner, J.L., \& Schwartz, J. S. (2007). Examining the dimensions of cancer-related information seeking and scanning behavior. Health Communication, 22(2), 153-167.

Norman, C. D., \& Skinner, H. A. (2006a). eHealth literacy: Essential skills for consumer health in a networked world. Journal of Medical Internet Research, 8(2), e9.

Norman, C. D., \& Skinner, H. A. (2006b). eHEALS: The eHealth literacy scale. Journal of Medical Internet Research, 8(4), e27. 
Nutbeam, D. (2000). Health literacy as a public health goal: A challenge for contemporary health education and communication strategies into the 21 st century. Health Promotion International, 15(3), 259-267.

Oprescu, F., Campo, S., Lowe, J., Andsager, J., \& Morcuende, J. A. (2013). Online information exchanges for parents of children with a rare health condition: Key findings from an online support community. Journal of Medical Internet Research, 15(1), e16.

Pang, P. C., Verspoor, K., Chang, S., \& Pearce, J. (2015). Conceptualising health information seeking behaviours and exploratory search: Result of a qualitative study. Health and Technology, 5(1), 45-55.

Park, H., \& Lee, E. (2015). Self-reported eHealth literacy among undergraduate nursing students in south korea: A pilot study. Nurse Education Today, 35(2), 408-413.

doi:http://dx.doi.org/10.1016/j.nedt.2014.10.022

Powell, J., Inglis, N., Ronnie, J., \& Large, S. (2011). The characteristics and motivations of online health information seekers: Cross-sectional survey and qualitative interview study. Journal of Medical Internet Research, 13(1), e20.

Public Health England. (2016). Government 5 A Day logo licensing guidelines. Retrieved July 27, 2016, from https://www.gov.uk/government/publications/government-5-a-day-logo

Quinn, S. (2016). hciParser. [Computer software]. Retrieved from, https://github.com/squinn36/hciParser

Rains, S. A. (2014). Health information seeking and the world wide web: An uncertainty management perspective. Journal of Health Communication, 19(11), 1296-1307.

Rains, S. A., \& Tukachinsky, R. (2015a). An examination of the relationships among uncertainty, appraisal, and information-seeking behavior proposed in uncertainty management theory. Health Communication, 30(4), 339-349.

Rains, S. A., \& Tukachinsky, R. (2015b). Information seeking in uncertainty management theory: Exposure to information about medical uncertainty and information-processing orientation as predictors of uncertainty management success. Journal of Health Communication, 20(11), 1275-1286.

Rowlands, G., Khazaezadeh, N., Oteng-Ntim, E., Seed, P., Barr, S., \& Weiss, B. D. (2013).

Development and validation of a measure of health literacy in the UK: The newest vital sign. $B M C$ Public Health, 13(1), 1. 
Rozmovits, L., \& Ziebland, S. (2004). What do patients with prostate or breast cancer want from an internet site? A qualitative study of information needs. Patient Education and Counseling, 53(1), 5764.

Sørensen, K., van den Broucke, S., Fullam, J., Doyle, G., Pelikan, J., Slonska, Z., \& Brand, H. (2012). Health literacy and public health: A systematic review and integration of definitions and models. BMC Public Health, 12(1), 1-13. doi:10.1186/1471-2458-12-80

Stellefson, M., Hanik, B., Chaney, J. D., \& Tennant, B. (2012). Analysis of ehealth search perspectives among female college students in the health professions using Q methodology. Journal of Medical Internet Research, 14(2), e60.

Stone, A. M., \& Jones, C. L. (2009). Sources of uncertainty: Experiences of alzheimer's disease. Issues in Mental Health Nursing, 30(11), 677-686.

Stone, A. M., Scott, A. M., Martin, S. C., \& Brashers, D. E. (2013). Using information to manage uncertainty during organ transplantation. Departures in Critical Qualitative Research, 2(1), 42-60.

Strekalova, Y. A. (2016). Finding motivation: Online information seeking following newborn screening for cystic fibrosis. Qualitative Health Research, 26(9), 1180-1190.

Tennant, B., Stellefson, M., Dodd, V., Chaney, B., Chaney, D., Paige, S., \& Alber, J. (2015). eHealth literacy and web 2.0 health information seeking behaviors among baby boomers and older adults. Journal of Medical Internet Research, 17(3), e70. doi:10.2196/jmir.3992 [doi]

Thompson, N. M., Bevan, J. L., \& Sparks, L. (2012). Healthcare reform information-seeking: Relationships with uncertainty, uncertainty discrepancy, and health self-efficacy. Journal of Communication in Healthcare, 5(1), 56-66.

van der Vaart, R., van Deursen, A. J., Drossaert, C. H., Taal, E., van Dijk, J. A., \& van de Laar, M. A. (2011). Does the eHealth literacy scale (eHEALS) measure what it intends to measure? validation of a dutch version of the eHEALS in two adult populations. Journal of Medical Internet Research, 13(4), e86.

van Deursen, A. J. A. M., \& van Dijk, J. A. G. M. (2009). Using the internet: Skill related problems in users' online behavior. Interacting with Computers, 21(5-6), 393-402.

doi:http://dx.doi.org/10.1016/j.intcom.2009.06.005 
Vevea, N. N., \& Miller, A. N. (2010). Patient narratives: Exploring the fit of uncertainty-management models of health care. The Review of Communication, 10(4), 276-289.

Weiss, B. D., Mays, M. Z., Martz, W., Castro, K. M., DeWalt, D. A., Pignone, M. P., Mockbee, J., \& Hale, F. A. (2005). Quick assessment of literacy in primary care: The newest vital sign. Annals of Family Medicine, 3(6), 514-522. doi:3/6/514 [pii]

World Health Organization. (2013). Health literacy. The solid facts. Retrieved July 27, 2016, from http://www.euro.who.int/en/health-topics/environment-and-health/urbanhealth/publications/2013/health-literacy.-the-solid-facts

World Health Organization. (2016a). Diabetes country profiles 2016. Retrieved July 27, 2016, from, http://www.who.int/diabetes/country-profiles/en/

World Health Organization. (2016b). Obesity and overweight. Retrieved July 27, 2016, from, http://www.who.int/mediacentre/factsheets/fs311/en/

World Health Organization. (2016c). Diabetes. Retrieved July 27, 2016, from, http://www.who.int/mediacentre/factsheets/fs312/en/

Zhang, Y., Sun, Y., \& Xie, B. (2015). Quality of health information for consumers on the web: A systematic review of indicators, criteria, tools, and evaluation results. Journal of the Association for Information Science and Technology, 66(10), 2071-2084. doi:10.1002/asi.23311 